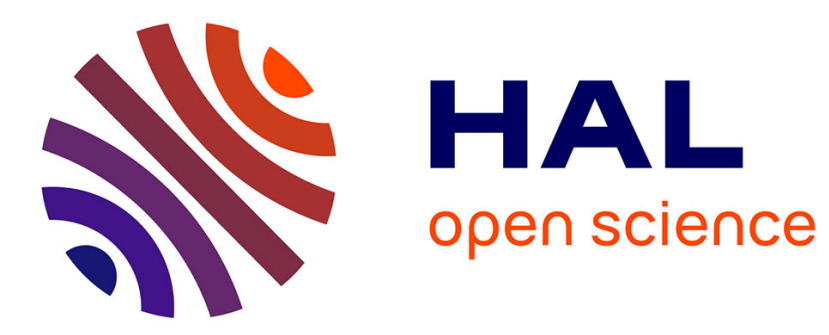

\title{
Combined experimental and numerical approach for the assessment of pressure generated by elastic compression bandage
}

Fanette Chassagne, Reynald Convert, Jérôme Molimard, Pierre Badel

\section{- To cite this version:}

Fanette Chassagne, Reynald Convert, Jérôme Molimard, Pierre Badel. Combined experimental and numerical approach for the assessment of pressure generated by elastic compression bandage. Computer Methods in Biomechanics and Biomedical Engineering, 2014, 17, pp.166 - 167. 10.1080/10255842.2014.931646 . hal-01405690

\author{
HAL Id: hal-01405690 \\ https://hal.science/hal-01405690
}

Submitted on 30 Nov 2016

HAL is a multi-disciplinary open access archive for the deposit and dissemination of scientific research documents, whether they are published or not. The documents may come from teaching and research institutions in France or abroad, or from public or private research centers.
L'archive ouverte pluridisciplinaire HAL, est destinée au dépôt et à la diffusion de documents scientifiques de niveau recherche, publiés ou non, émanant des établissements d'enseignement et de recherche français ou étrangers, des laboratoires publics ou privés. 


\title{
Combined experimental and numerical approach for the assessment of pressure generated by elastic compression bandage
}

\author{
Fanette Chassagne* $+\ddagger$, Reynald Convert $\dagger$, Jérôme Molimard $\uparrow$, Pierre Badel $\dagger$ \\ $\dagger$ †GF, UMR 5307, École Nationale Supérieure des Mines, CIS-EMSE, CNRS, Saint-Étienne, France
}

$\$$ Thuasne, BP243, 92307 Levallois-Perret cedex, France

Keywords: Numerical simulation; leg compression; bandage; subject-specific

\section{Introduction}

Elastic compression bandage is a common treatment for venous or lymphatic disorders. Even though the efficacy of this treatment is admitted, its mechanism remains poorly understood. The success of the treatment depends on the applied pressure, which depends on the bandage tension and the curvature of the limb (Laplace's Law), the number of layers of the bandage, its components (padding layer, crepe ...) and elastic properties, and the interactions between bandages and leg. To better understand the action of compression bandage, many interface pressure measurements have been done, but those measurements only give local information and for now, the whole pressure distribution on the leg is not known. Also, due to complex leg curvature and to bandage-leg and bandage-bandage interactions, the Laplace's law is not sufficient to give a fine description of the pressure fields. Some simulations of the leg compression exist. Most of them are modeling the action of a compression sock on a leg [1][2], whose mechanical properties are more or less complex [3]. As far as we know, the simulation of bandage application on the leg has never been done yet.

The aim of this communication is to present a first numerical model of the action mechanisms of bandages onto the skin developed through an experimental-numerical approach. A subject-specific FE model of bandage application is developed and compared with experimental measurements on two subjects.

\section{Methods}

\section{Pressure measurements}

The elastic bandages used in this work were the Biflex $^{\circledR} 16$ (B16) and Biflex ${ }^{\circledR} 17$ (B17), manufactured by THUASNE. The Biflex ${ }^{\circledR} 17$ is stiffer ('stronger') than Biflex ${ }^{\circledR} 16$. The interface pressure is measured for 3 subjects in order to be compared with the model data. The sensors (PicoPress ${ }^{\circledR}$ ) were located at two reference heights at which 3 sensors were located around the leg (medial, lateral and posterior locations). Both bandages, B16 and B17, were applied on the leg in the supine position, in a spiral technique with 2 and 3 layers. The interface pressure was measured in the supine position and the foot was slightly raised in order to prevent any contact between the examination bed and the calf. Another measurement was carried out in standing position, after $30 \mathrm{~s}$ at rest in this position.

\section{Leg geometry and mechanical properties}

In order to have a subject-specific model, the leg was scanned with a structured light 3D scanner (Artec 3D ${ }^{\circledR}$ scanner), to obtain the external geometry. In the area of interest, from the ankle to the tibial plateau, horizontal sections were defined every 5 to $10 \mathrm{~mm}$. The leg geometry was obtained by a sweeping operation along these sections. The bone geometries were extracted from anatomical slices of the 'Visible Human Server' (EPFL) and were scaled to fit the leg geometry. The complete geometry was meshed in Abaqus $^{\circledR}$ with 4-node linear tetrahedron elements. The leg tissue was considered as a single homogeneous material consisting in equal proportion of adipose tissue and muscle tissue, modelled with a neoHookean material whose parameters were taken from the literature [3].

\section{Bandage geometry and mechanical properties}

The only known parameter of the bandage model was its longitudinal stretch which is equal to 1.3 once the bandage has been applied on the leg (calibration marker printed on the bandage). For this reason, the bandage geometry was modelled from the external leg geometry, whose horizontal sections were approximated by Fourier polynomials. From these sections, it was possible, with a custom meshing programme in Matlab ${ }^{\circledR}$, to build any bandage model knowing its width (in this case $100 \mathrm{~mm}$ ) and the number of layers ( 2 or 3 ). The bandage was meshed with 4-node shell elements with reduced integration. Bandage material was considered as orthotropic linear elastic. For both bandage types, the mechanical properties have been measured experimentally (planar tension, uniaxial tension, shear, bending tests). $\quad v_{12}=$ 0.053

\begin{tabular}{|c|c|c|}
\hline \multirow{3}{*}{ Biflex $^{\circledR} 16$} & $\begin{array}{c}\mathrm{E}_{1}=0.192 \mathrm{~N} . \mathrm{mm}^{-1} \\
\mathrm{E}_{2}=0.297 \mathrm{~N} . \mathrm{mm}^{-1}\end{array}$ & $\begin{array}{c}v_{12}=0.053 \\
\mathrm{G}=0.09 \mathrm{~N} . \mathrm{mm}^{-1}\end{array}$ \\
\cline { 2 - 3 } & \multicolumn{2}{|c|}{ Tension for a stretch equal to $1.3: 57.6 \mathrm{cN} / \mathrm{cm}$} \\
\hline \multirow{3}{*}{ Biflex $^{\circledR} 17$} & $\mathrm{E}_{1}=0.379 \mathrm{~N} . \mathrm{mm}^{-1}$ & $v_{12}=0.066$ \\
& $\mathrm{E}_{2}=0.604 \mathrm{~N} . \mathrm{mm}^{-1}$ & $\mathrm{G}=0.24 \mathrm{~N} . \mathrm{mm}^{-1}$ \\
\cline { 2 - 3 } & \multicolumn{2}{|c|}{ Tension for a stretch equal to $1.3: 113.6 \mathrm{cN} / \mathrm{cm}$} \\
\hline
\end{tabular}

Table 1: Bandage mechanical properties 


\section{Simulation strategy}

The simulation was done in 2 steps:

- bandage dilation (displacement along the radial direction)

- bandage relaxation and activated contact

The contact between the bandage and the leg allows no penetration and had a friction coefficient equal to 0.3 . There was no contact between the different bandage layers.

\section{Results and Discussion}

\section{Experimental results}

The main results and trends observed experimentally are as follows:

- the pressure was higher with 3 layers than with 2 layers (for the large circumference : pressure with 2 layers $35.9 \pm 7.6 \mathrm{mmHg}$ and with 3 layers $64.9 \pm 9.6 \mathrm{mmHg}$ )

- the pressure in the supine position was the same as the one in the standing position

- the pressure exerted by the bandage B17 was about 1.55 times higher than the one exerted by bandage B16 (for the large circumference : pressure with B16 $43.5 \pm 14.6 \mathrm{mmHg}$ and with

$$
\text { B17 } 57.33 \pm 17.0 \mathrm{mmHg} \text { ) }
$$

Note that, according to the elastic properties of the different bandages, the pressure exerted by the B17 was expected to be twice as high as the one exerted by the B16.

\section{Numerical results}

Two cases are presented here: a small and a large leg circumference. For the sake of verification, the bandage stretch was checked at the end of the simulation. It was about 1.29. The small difference with the expected stretch is mainly due to the decrease of the leg circumference (its cross section becomes rounder) resulting from the compression of the leg. The pressure was extracted at the same measurement points as for the experimental measurements. The pressure with the bandage B17 was twice as high as with the bandage B16, which could have been expected because of the two bandage mechanical properties, and the pressure with 3 layers was about $73 \%$ higher than with 2 layers.
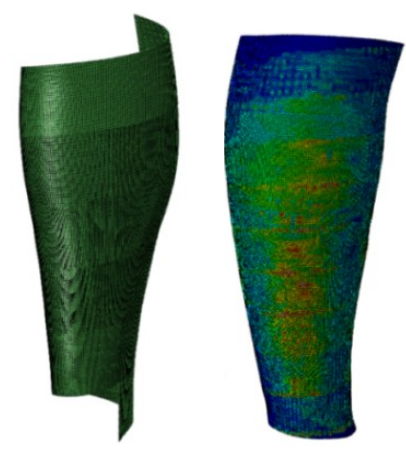

Figure 1: bandage and pressure map The range of pressure obtained with the model was in agreement with the pressure distribution levels predicted with the Laplace's law for both legs.

\section{Discussion}

The pressure values from the simulation were compared with the experimental data. Simulation values were lower than experimental data by $27 \%$ for the B17 to $54 \%$ for the B16.

The study of the experimental and numerical results has led to the following remarks:

- the difference between the numerical and the experimental results is higher for the B16 than the B17

- experimentally, the ratio between the pressure exerted by a B17 and the one exerted by a B16 is much lower than expected (1.55 instead of 2)

- the model was used to assess the influence of bandage strain variation and it was shown that 1 to $2 \%$ pressure increase is induced per $\%$ strain increase whereas a $10 \%$ strain increase leads to a barely dinstinguable shape change of the calibration marker.

- an uncertainty exists regarding the bandage mechanical properties (complex mechanical behavior and important hysteresis).

Hence, it is necessary to improve a few points:

- a better control of the bandage stretch for the bandage application is required

- the interaction between the different layers of the bandage have to be taken into account for the simulation.

\section{Conclusions}

This study consists in an experimental and numerical approach of a non-trivial problem, such as the assessment of pressure distribution exerted by elastic compression bandage and questions the supposed action mechanism of bandage.

\section{References}

[1] Dai X.Q., Lui R., Zhang M., et Kwok Y.L., « Numerical simulation and prediction of skin pressure distribution applied by graduated compression stockings », Comput. Text., vol. 55, p. 301-309, 2007.

[2] R. Liu, Y.-L. Kwok, Y. Li, T.-T. Lao, X. Zhang, et X. Q. Dai, « A three-dimensional biomechanical model for numerical simulation of dynamic pressure functional performances of graduated compression stocking (GCS) », Fibers Polym., vol. 7, no 4, p. 389-397, déc. 2006.

[3] L. Dubuis, S. Avril, J. Debayle, et P. Badel, «Identification of the material parameters of soft tissues in the compressed leg ", Comput. Methods Biomech. Biomed. Engin., vol. 15, no 1, p. 3-11, janv. 2012. 